\title{
PROCESO DE EVALUACIÓN FORMATIVA EN LA REALIZACIÓN DE UN VÍDEO PARA TICS EN UN CENTRO BILINGÜE
}

Formative Assessment process in the elaboration of a video for ICT subject in a bilingual high school

Processo de avaliação formativa em fazer um vídeo para TIC em uma escola bilíngüe

\section{César Lozano Gallego}

IES Valles del Luna, Santa María del Páramo (León), España. Teléfono: +34 6992683

\section{Correo electrónico cesar.lozano.gallego@gmail.com}

\section{Resumen}

Se presenta un caso práctico y real del proceso de evaluación formativa aplicado en Tecnologías de la Información y la Comunicación (4ESO) en el IES Valles del Luna de Santa María del Páramo (León). Bajo el pretexto de la celebración del Día Mundial del Medio Ambiente (5 de junio), los alumnos elaboraron un guión en inglés y fueron los actores para la grabación de cortometrajes utilizando diferentes recursos tecnológicos y audiovisuales aprendidos en clase, tales como maquetación de vídeos (MovieMaker, Sony Vegas), maquetación de audio (Audacity) y técnicas videográficas (croma). Previamente se les presentó la escala descriptiva ('rúbrica') con los diferentes aspectos a valorar, así como sus distintos niveles de logro y valor asignado.

Palabras clave: Evaluación formativa; Rúbrica; TICs

\begin{abstract}
A practical and real case of the formative assessment process applied in Information and Communication Technologies $\left(4^{\circ} \mathrm{ESO}\right)$ in the IES Valles del Luna de Santa María del Páramo (León) is presented. Under the pretext of celebrating World Environment Day (June 5), the students produced a script in English and were the actors for recording short films using different technological and audiovisual resources learned in class, such as video layout (MovieMaker, Sony Vegas), audio layout (Audacity) and video techniques (chroma). Previously the descriptive scale ('rubric') was presented with the different aspects to be evaluated, as well as their different levels of achievement and assigned value.
\end{abstract}

Keywords: Formative assessment; rubric; ICT 


\section{Resumo}

Um processo de avaliação formativa prático e real aplicado em Tecnologia de Informação e Comunicação ( $\left.4^{\circ} \mathrm{ESO}\right)$ no caso IES Valles Luna de Santa María del Páramo (León) é apresentado. Sob o pretexto de celebrar o Dia Mundial do Ambiente (5 de junho), os alunos desenvolveram um script em Inglês e foram os atores para gravar filmes curtos usando diferentes recursos tecnológicos e audiovisuais aprendidas em sala de aula, como vídeos de editoração eletrônica (MovieMaker, Sony Vegas), áudio layout (Audacity) e técnicas videográficos (croma). Anteriormente, eles apresentados com a escala descritiva ('rúbric') com os diferentes aspectos a serem avaliados, bem como diferentes níveis de realização e valor atribuído.

Palavras-chave: avaliação formativa; rubrica; TIC

\section{Introducción}

En este trabajo nos centramos en el proceso de evaluación formativa llevado a cabo durante la elaboración de un vídeo, un caso real de evaluación formativa que tiene como objetivos generales mejorar en: (1) el proceso de aprendizaje de nuestro alumnado; (2) nuestra competencia docente día a día; (3) los procesos de enseñanza-aprendizaje que desarrollamos en nuestras aulas con nuestro alumnado (López-Pastor, 1999, 2012).

\section{Contextualización}

La experiencia se desarrolló en el centro educativo "IES Valles del Luna" de Santa María del Páramo (León), centro que oferta Enseñanza Secundaria Obligatoria y Bachillerato. El IES se encuentra adscrito al programa bilingüe (inglés), afectando a todos los cursos de la ESO. Las materias no lingüísticas en bilingüe son Ciencias de la Naturaleza, Educación Física, Tecnología, Física y Química y Tecnologías de la Información y la Comunicación (TICs).

Esta experiencia tuvo lugar en la materia de TICs durante el segundo trimestre, con el grupo bilingüe de $4^{\circ} \mathrm{ESO}$, compuesto por 10 alumnos. Se llevó a cabo la Unidad Didáctica (UD) “Lights, camera, action!”, con el objetivo de producir diversos cortometrajes con tema medioambiental dedicados para la celebración del Día Mundial del Medio Ambiente (5 de junio). 
La UD, que duró 8 sesiones (4 semanas, 2 h semanales), se desarrolló en cinco fases: (1) conocimiento del vocabulario específico, (2) explicación y planificación del trabajo, (3) elaboración de diferentes tomas, (4) montaje del vídeo y (5) entrega del vídeo y visionado grupal.

Los objetivos específicosse centraron en que el alumno fuera capaz de:

- Editar audio mediante herramientas informáticas.

- Montar vídeos para crear un cortometraje.

- Utilizar la técnica del ‘croma’ en la grabación de vídeos.

- Descargar música/imágenes/vídeos atendiendo a sus derechos de autor.

- Utilizar la escala de valoración como instrumento asociado a una evaluación formativa.

\section{Diseño y desarrollo}

A continuación, se realizará una breve explicación que facilite la comprensiónde cada una de las cinco fases en las que se desarrolló la UD:

1. Conocimiento del vocabulario específico: al inicio de la unidad se repasaron las principales técnicas de grabación, incidiendo especialmente en el 'croma' como forma de conseguir escenarios de manera sencilla. Asimismo, se hizo entrega de información acerca del tema medioambiental para dar ideas de cara al diseño del guión.

2. Explicación y planificación del trabajo: este trabajo se llevó a cabo en grupos de 2 personas (5 grupos en total). Cada grupo tuvo que elaborar un cortometraje en el que aparecieran, por lo menos, los dos integrantes, actuando según lo establecido por ambos en un guión previo. Desde el inicio se hizo entrega de la escala de valoración (“rúbrica”) donde aparecían los criterios con los que ibana ser evaluados y calificados (Tabla 1).

3. Elaboración de diferentes tomas: la UD se desarrolló completamente durante las clases de TICs. Los grupos comenzaron elaborando un guión con el tema medioambiental a tratar, indicando asimismo los diferentes escenarios que necesitarían para ubicar las escenas (y que insertarían mediante la técnica del 'croma'). Como mínimo, deberían elaborar un guión en el que fuera necesario que 
aparecieran los dos integrantes del grupo, aunque también podían pedir la colaboración de otros miembros de la clase. Posteriormente, se procedería a la grabación de las diferentes escenas diseñadas en el guión.

4. Montaje del vídeo: con las escenas ya grabadas, se procedió al montaje del vídeo en la sala de Nuevas Tecnologías del centro. Durante este periodo, el docente llevó a cabo el proceso de corrección y feedback detallado en la Tabla 1.

5. Entrega del vídeo y visionado grupal. Tras la entrega final, cada vídeo fue visualizado por todos los grupos. Se realizó un pequeño debate sobre los puntos fuertes y aspectos a mejorar de cada vídeo.

\section{Evaluación}

El proceso de evaluación formativa integrado durante la elaboración del video busca que los grupos consigan realizar el mejor el trabajo posible antes de su entrega final. Para llevar a cabo dicha evaluación formativa, el docente se sirvió de una escala de valoración (Anexo 1). Esta escala de valoración constituye un instrumento de evaluación fundamental, que se utilizó durante el proceso de elaboración del video en grupos, con el fin de comparar el trabajo que los alumnos estaban realizando y las variables que aparecían en la escala, estableciendo las correcciones y/o alternativas con el fin de identificar errores y poder orientarlos. Cada uno de estos aspectos de valoración está constituido por sus criterios o niveles de logro, tal y como se observa en el Anexo 1. Esta misma escala fue utilizada nuevamente como instrumento de evaluación durante la fase final de la unidad, ya que, tras la visualización de cada uno de los vídeos, cada grupo procedió a la autoevaluación y coevaluación grupal a través de la cumplimentación de dicha escala.

Los resultados obtenidos por parte de los alumnos (un total de 10) fueron:

- Sobresaliente: 8 alumnos

- Notable: 2 alumnos.

Como puede verse, pos resultados obtenidos fueron muy positivos. Parece evidente que el hecho de establecer correcciones durante el proceso favorece el aprendizaje de los alumnos, así como la obtención de una mejor calificación final. 


\section{Conclusiones}

La entrega inicial de una escala de valoración hizo que el alumnado fuese más responsable, al conocer desde el principio los criterios con los que iban a ser evaluados. De la misma manera, el proceso de autoevaluación y coevaluación que llevó a cabo el propio alumno puede conducir a que se incremente su nivel de autonomía y su competencia de aprender a aprender.

Se comprueba que los alumnos han sido capaces de seguir la serie de condiciones explicitadas en la escala de valoración, pero también de identificar los aspectos positivos y reconocer los puntos negativos de su propio trabajo y el de los compañeros.

\section{Referencias}

López-Pastor, V. M. (1999). Prácticas de evaluación en Educación Física: estudio de casos en Primaria, Secundaria y Formación del Profesorado. Valladolid: Universidad de Valladolid.

López-Pastor, V. M. (2012). Evaluación Formativa y Compartida en la Universidad: clarificación de conceptos y propuestas de intervención desde la Red Interuniversitaria de Evaluación Formativa. Psychology, Society \& Educatión, 4(1), 113-126. 


\section{Anexo 1. Escala de valoración utilizada en la experiencia}

\begin{tabular}{lcccc}
\hline $\begin{array}{l}\text { Aspectos } \\
\text { a valorar }\end{array}$ & $\begin{array}{c}\text { Sub } \\
\text { valor }\end{array}$ & \multicolumn{1}{c}{ Criterios o niveles de logro } & $\begin{array}{c}\text { Valor } \\
\text { máximo }\end{array}$ \\
\hline $\begin{array}{l}\text { Número } \\
\text { escenas }\end{array}$ & 10 & 4 o más escenas & 10 \\
& 7 & $\begin{array}{l}\text { 3 escenas } \\
\text { 2 escenas } \\
1 \text { escena }\end{array}$ & \\
& 0 & & 10 \\
\hline Voz hablada & 10 & Voz en todas las escenas & 10 \\
en las escenas & 7 & Falta voz en una escena \\
& 5 & Falta voz en dos escenas & \\
& 0 & Falta voz en tres o más escenas & \\
\hline $\begin{array}{l}\text { Música } \\
\text { fondo }\end{array}$ & 10 & La música ajusta su volumen con los diálogos & \\
& 5 & Aparece algún fallo en el ajuste de la música con diálogos & \\
& 0 & No se inserta música, o esta no se ajusta a los diálogos & \\
\hline
\end{tabular}

Corrección de 10 No aparecen ruidos en el sonido, el diálogo se entiende 10 audio perfectamente

5 Aparece algún ruido o alguna palabra no se entiende bien

$0 \quad$ Cuesta entender los diálogos, o el ruido no se ha corregido

\begin{tabular}{llll}
\hline Uso y manejo & 10 & Se utiliza el croma en todas las escenas y no se aprecian fallos & 10
\end{tabular}

del croma $\quad 7$ Se utiliza el croma en $3 / 4$ partes de las escenas y/o se aprecia algún fallo

5 Se utiliza el croma en la mitad de las escenas y/o se aprecian fallos corregibles

$0 \quad$ No se utiliza, o se utiliza en menos de la mitad de las escenas, y se aprecian muchos fallos corregibles

\begin{tabular}{|c|c|c|c|}
\hline $\begin{array}{lr}\text { Fuentes } & \text { de } \\
\text { imágenes } & \text { y } \\
\text { sonidos } & \end{array}$ & $\begin{array}{l}10 \\
7 \\
5 \\
0\end{array}$ & $\begin{array}{l}\text { Se recogen y explicitan todas las fuentes de imágenes y sonido } \\
\text { utilizadas } \\
\text { Falta una referencia } \\
\text { Faltan } 2 \text { referencias } \\
\text { Faltan } 3 \text { o más referencias }\end{array}$ & 10 \\
\hline $\begin{array}{lr}\text { Derechos } & \text { de } \\
\text { imágenes } & y \\
\text { sonidos } & \end{array}$ & $\begin{array}{c}10 \\
0\end{array}$ & $\begin{array}{l}\text { Se utilizan fuentes sin derechos de autor } \\
\text { Se utilizan fuentes con derechos de autor }\end{array}$ & 10 \\
\hline $\begin{array}{l}\text { Explicaciones } \\
\text { en inglés }\end{array}$ & $\begin{array}{l}10 \\
7 \\
5 \\
0\end{array}$ & $\begin{array}{l}\text { Corrección en su uso } \\
\text { Aparece algún fallo puntual } \\
\text { Aparecen varios fallos } \\
\text { Aparecen muchos fallos }\end{array}$ & 10 \\
\hline $\begin{array}{l}\text { Contenido del } \\
\text { vídeo }\end{array}$ & $\begin{array}{c}10 \\
7 \\
5 \\
0\end{array}$ & $\begin{array}{l}\text { Se aprecia una sucesión lógica en el guión } \\
\text { Podría mejorarse algún aspecto del guión } \\
\text { Se entiende la trama pero necesitaría ser mejorada } \\
\text { No se entiende la trama del vídeo }\end{array}$ & 10 \\
\hline Creatividad & $\begin{array}{l}10 \\
7 \\
5 \\
0\end{array}$ & $\begin{array}{l}\text { El vídeo es original y creativo. Valoración global muy positiva } \\
\text { El vídeo podría ser mejorado en un aspecto puntual aunque la } \\
\text { valoración global es muy positiva. } \\
\text { El vídeo podría ser mejorado en varios aspectos. La valoración } \\
\text { global es aceptable. } \\
\text { El vídeo necesita ser reelaborado. }\end{array}$ & 10 \\
\hline
\end{tabular}


Condiciones iniciales para aprobar (requisitos):

- $\quad$ Grupos de 2-3 personas

- Formato de entrega: mp4 o similar (formato de vídeo)

- Al menos valoración de 5 puntos en cada uno de los aspectos siguientes

- Todos los miembros del grupo participan en la maquetación del vídeo

- Todos los miembros del grupo participan como actores del vídeo

- $\quad$ Estructura del vídeo: introducción-nudo-desenlace

- Concentración y seriedad durante la reproducción de los vídeos 